\title{
La gestión municipal: ¿cómo administrar las plazas y los mercados de la ciudad de México? 1824-1840
}

\author{
Municipal Management: How to Administrate the \\ Squares and Markets of Mexico City? 1824-1840
}

\author{
Gisela Moncada González \\ Instituto de Investigaciones Históricas-UNAM | gismoncada@hotmail.com
}

\begin{abstract}
Resumen
El texto analiza la gestión de los servicios públicos en la ciudad de México y, en particular, la administración de las plazas y los mercados a través de contratas a particulares. La problemática se centra en las dificultades que enfrentó la administración municipal para regular el comercio urbano. La fuente documental empleada son las Ordenanzas municipales de 1840 y el estudio detallado de las comisiones que integraban al Ayuntamiento de México entre 1810 y 1840. La investigación concluye que la falta de un orden jurídico que regulara la gestión municipal provocó una mala organización y planeación en los servicios públicos de la ciudad. Por ello, las contratas, que parecían una salida eficiente en la administración municipal, terminaron por convertirse en negocios entre particulares, debido a la incapacidad del gobierno para vigilarlos y regularlos, así como por la falta de recursos económicos para sostenerlas.
\end{abstract}

Palabras clave: plazas; mercados; comercio urbano; contrata; gestión municipal.

\section{Abstract}

This text analyzes the management of public services in Mexico City and, in particular, the administration of squares and markets through contracts with hired individuals. The problem centers on the difficulties faced by the municipal administration in regulating urban commerce. The documentary source used here are the Ordenanzas municipales of 1840 and a detailed study of the commissions comprising the Mexico City Government between 1810 and 1840. The research concludes that the lack of a legal framework to regulate municipal management resulted in poor organization and planning of the city's public services. Thus, contracts, which appeared to be an efficient solution for the municipal administration, ended up becoming a business arrangement between individuals, due to the government's inability to oversee and regulate it, as well as the lack of economic resources to sustain it.

Key words: squares; markets; urban commerce; hiring; municipal management.

Fecha de recepción: 28 de abril de 2014 Fecha de aceptación:16 de octubre de 2014 


\title{
La gestión municipal: ¿cómo administrar las plazas y los mercados de la ciudad de México? 1824-1840
}

\author{
Gisela Moncada González
}

\section{LA MUNICIPALIDAD Y SU PAPEL EN LA GESTIÓN DE SERVICIOS}

a administración de los servicios públicos en la ciudad de México du-
rante la primera mitad del siglo xix enfrentó serias dificultades: por un lado, la falta de recursos económicos municipales; por otro, las tensiones políticas entre la autoridad municipal y la autoridad central dejaron un espacio libre de gobierno en el quehacer de las municipalidades. La ausencia de consensos entre la clase política para organizar los servicios urbanos en la ciudad de México se hicieron evidentes durante los primeros años de vida independiente.

El Ayuntamiento debía garantizar la buena policía, la cual se relacionaba con las tareas de administración, servicios y facultades de control sobre una población en un territorio determinado, así como promover el bien público. Dichas tareas se centraban en asegurar el abasto a los habitantes, equidad en las medidas utilizadas en el comercio, limpieza de las calles, alumbrado, mantenimiento de jardines, seguridad, higiene, control de vagos y obligaciones religiosas, por mencionar algunas (Gortari, 2002, p. 117). Realizar todas estas tareas implicaba a la municipalidad contar con recursos económicos y capacidad de autogestión, es decir, capacidad para tomar decisiones al interior de la corporación y, al mismo tiempo, disponer de dinero para realizar las diligencias; desafortunadamente esta condición no se cumplió a cabalidad.

Los estudiosos de las municipalidades señalan que uno de los principales problemas que enfrentaron estas ante la creación de la nueva nación independiente, particularmente durante la primera república federal, fue la carencia de un marco regulatorio que normara los asuntos cotidianos; las autoridades de gobierno, en su afán de construir un Estado fuerte, se concentraron en legislaciones de partidos y de poderes, olvidando la dimensión municipal (Salinas, 1999, p. 192). 
Si bien es cierto que la Constitución de 1824 no contempló un apartado para las leyes municipales, es pertinente reconocer que el propio sistema republicano no tenía entre sus facultades hacer leyes municipales, pues cada entidad tenía la capacidad de elaborar sus propias legislaciones; además, aspectos menores de la vida cotidiana, como los servicios públicos, correspondían a los ayuntamientos. En ese sentido, al no haberse promulgado nuevas disposiciones para las municipalidades, bajo la primera república federal, se mantuvo vigente la Constitución de Cádiz de 1812, la cual otorgaba a los ayuntamientos ciertas facultades y atribuciones, sobre todo en materia del cuidado de la buena policía (Miranda, 1998, p. 64).

¿Qué implicaciones tuvo carecer de un marco regulatorio municipal en las primeras décadas del siglo xIX? El Ayuntamiento de la ciudad de México tuvo que gobernar improvisando la gestión de algunos servicios, utilizando los conocimientos previos que tenía sobre la organización municipal y utilizó la emisión de bandos a manera de reglamentación; así, el arriendo y la contrata fueron las recetas aplicadas. La administración de las plazas y los mercados fue todo un experimento administrativo, ya que la municipalidad se guio bajo la lógica republicana de la libertad comercial y la apertura para abrir contratas a particulares para la administración de los mercados, pero operó con la maquinaria administrativa del virreinato, aunque tuvo que implementar algunos cambios, como fue la creación de nuevas comisiones, que más adelante se analizarán.

\section{LA ADMINISTRACIÓN DE LAS PLAZAS Y LOS MERCADOS EN LA PRIMERA REPÚBLICA FEDERAL}

Hemos señalado que uno de los problemas que enfrentaron las municipalidades durante la primera república federal fue prescindir de un marco regulatorio capaz de normar los asuntos de la vida cotidiana de los habitantes de la ciudad de México y, por ello, fue a través de bandos y "Avisos al público" como el Ayuntamiento capitalino gobernó la ciudad, resolviendo día a día las distintas demandas de sus habitantes.

En materia de abasto, continuó como una de las obligaciones del Ayuntamiento velar por la abundancia de los alimentos y la buena calidad de estos. Cabe aclarar que en el virreinato operaba la Junta de Abastos, la cual vigilaba que los víveres estuvieran bien distribuidos en las plazas y los mercados de la ciudad y, además, se encargaba del cobro del "derecho de plaza"

\section{(1)(1) $\$$}


a todos los sitios de venta en la ciudad. A través de la Fiel Ejecutoria -órgano dependiente del Ayuntamiento- se realizaban visitas periódicas a los expendios (Quiroz, 2005). ${ }^{1}$

Durante la primera república federal se dieron varios cambios en las municipalidades; es decir, si bien no se modificó la estructura del Ayuntamiento, sí se incrementó el número de sus comisiones. Lo anterior en respuesta a las necesidades de los habitantes y ante las circunstancias que la propia ciudad enfrentó.

Por ejemplo, el crecimiento del comercio urbano rebasó la capacidad de inspección por parte del Ayuntamiento: había puestos dentro y fuera de los principales mercados, las calles de la ciudad estaban llenas de vendedores ambulantes, las esquinas de mayor tránsito también presentaban el mismo fenómeno. Esto obligó a las autoridades municipales a distinguir dos tipos de expendios: las plazas y los mercados, ya que cada uno de ellos presentaba condiciones particulares.

Se les daba la categoría de plazas aunque en realidad eran tianguis situados en determinadas plazas de la ciudad, en las cuales se instalaban puestos movibles, las llamadas "sombras"; estas las colocaban los vendedores por la mañana y por la tarde las retiraban. En los mercados se localizaban puestos fijos llamados en la época cajones. Obviamente, la renta de un cajón era mucho más costosa que el pago por la "sombra", la mayoría de los vendedores de los tianguis instalados en las plazas eran comerciantes indígenas de escasos recursos $y$ con pocos productos para vender. En cambio, los comerciantes de un mercado eran vendedores con mayores ingresos y mayor capacidad de almacenaje.

Es importante señalar que durante la primera república federal el único mercado formal que existía construido de mampostería era el Parián, y aunque este mercado se caracterizó por vender productos de lujo, para este periodo se sabe que comenzó a albergar comerciantes de alimentos (Moncada, 2013a, p. 172).

Las Actas de Cabildo dan cuenta de la preocupación de los alcaldes y regidores por mejorar las condiciones de los mercados, hubo varios proyectos para la construcción de mercados fijos, sin embargo no se lograron concretar en la república. Durante este periodo fue recurrente que el Ayuntamiento moviera a los ambulantes de las calles y estos al día siguiente se

${ }^{1}$ Para conocer la legislación virreinal y el control por parte del Ayuntamiento de México en la regulación del comercio de la carne en la ciudad de México entre 1750 y 1812, véase Quiroz, 2005.

\section{()(1) $\$$}


colocasen en otro sitio. La municipalidad sabía que la falta de mercados fijos facilitaba la instalación de ambulantes alrededor de las plazas, pues estas eran espacios abiertos en los que no se distinguía el afuera del adentro. Así que como una forma de remediar el crecido comercio y controlar tanto el orden como la recaudación que de este comercio se obtenía, el Ayuntamiento recurrió a la vieja práctica utilizada en el virreinato de delegar a particulares dicha tarea, aunque con matices distintos.

\section{ANTECEDENTES DEL ASENTISTA DE PLAZA}

La administración del comercio menudo en las plazas y los mercados capitalinos ha sido históricamente una ardua tarea para el gobierno de la ciudad. Organizar a sus vendedores, cobrar la renta por el lugar que ocupan, mantener el orden, la limpieza de los expendios, así como regular los horarios y los productos a comerciar ha implicado a la administración de la ciudad instaurar distintos dispositivos para reglamentarlo. En el siglo XVIII la administración de las plazas y los mercados estaba a cargo de un asentista, modalidad implementada por el Ayuntamiento como un mecanismo de control para poder cobrar el impuesto, llamado "derecho de plaza", a los vendedores que se instalaban en la Plaza Mayor a expender sus productos.

El asentista entregaba cierta cantidad al Ayuntamiento al inicio del año a manera de fianza, se le denominaba "concesión del asiento". Entre las obligaciones del asentista destacaba la organización y asignación de puestos a los vendedores, el buen trato a los indígenas, el cobro del derecho de plaza y mantenerla limpia, aunque esta última tarea no se formalizó del todo (Toris, 2014 , p. 45$)^{2}$

El asentista funcionaba como un mediador entre los comerciantes y el Ayuntamiento, para los primeros era como un líder de plaza con quien negociaban sus peticiones y solucionaban sus conflictos; para los segundos, fungió como un gestor municipal que le redujo costos administrativos a la corporación, ya que depositaba en esta figura la administración del comercio urbano, por lo menos de un espacio específico. Francisco Cameros fue uno de los últimos asentistas de la Plaza Mayor. Tras su muerte en 1745, el Ayuntamiento intentó recuperar la gestión de la administración de las plazas y eliminó la

${ }^{2}$ El encargado fue el asentista Francisco Cameros de 1694 hasta 1741.

\section{()(1) $\$$}


figura del asentista. Así que, en 1753, se encomendó a uno de los regidores el cargo de "administrador de puestos y mesillas" (Toris, 2014, pp. 41-47).

La experiencia del Ayuntamiento de depositar en un tercero la administración de un servicio público, como fue la administración de las plazas y los mercados, no había sido del todo positiva. Una de las razones fue porque al no haber claridad en las facultades de este, muchas veces los administradores se enriquecían a costa de la gestión pública (Toris, 2014, pp. 41-47). No obstante, habría que agregar que no siempre se trató de un abuso de los administradores como a veces la historiografía los ha encasillado (Lau, 2003, pp. 221-285). ${ }^{3}$ En ocasiones los administradores se comprometían a determinada tarea, pero los rebasaba la complejidad de la ciudad. Por ejemplo, las contratas que más incumplimientos presentaron fueron las concernientes a la limpia, ya que ante una inundación o un estancamiento de aguas, se requería algo más que escobas y dos carros, muchas veces no se contaba con los instrumentos de trabajo específicos y se improvisaba. ${ }^{4}$

Los experimentos para controlar el comercio urbano fueron diversos, con la instauración de las reformas borbónicas se generó un cambio importante en la administración política y económica de todo el virreinato; en lo que corresponde al comercio urbano hubo modificaciones importantes. Por ejemplo, se buscó una mayor fiscalización en las transacciones comerciales, para ello hubo que ampliar el número de recaudadores. En el ámbito de la cotidianidad se promovieron ideas sobre la higiene, la libre circulación, la limpieza de las calles, la prevención de incendios, el establecimiento de alumbrado en las calles y la prohibición del comercio nocturno. Bajo esta nueva lógica, se observa que en el nuevo ideario urbano no cabían las prácticas tradicionales como la venta callejera y nocturna, tampoco la obstrucción de las banquetas (Olvera, 2007, p. 421).

No obstante, el ideal borbónico se topó con diversas prácticas y costumbres de las autoridades y habitantes de la ciudad de México que limitaron la puesta en marcha de varias normativas. Cuando tomó posesión como virrey

${ }^{3}$ Ana Lau Jaivén sostiene que a menudo los contratistas se enriquecían de las contratas y no cumplían con sus tareas. Lo que aquí se plantea es que al margen de existir esas prácticas, también hubo contratistas que no cumplieron con sus tareas debido a que no contaban con la infraestructura para realizar sus labores, como fue el caso de la limpia o el reparo de caminos. Incluso, en la administración de los mercados, en ocasiones los contratistas no realizaban sus tareas a cabalidad porque la complejidad de la ciudad había rebasado su capacidad de administración.

${ }^{4}$ Actas de Cabildo. 6 de abril de 1836. Vol. 156a. Archivo Histórico del Distrito Federal (en adelante AHDF), México.

\section{()(1) $\$$}


el segundo conde de Revillagigedo se intentaron formalizar varias prácticas del comercio urbano, una de ellas fue la elaboración del Reglamento de Mercados en 1791, el cual aclaraba el lugar de venta de los productos, los horarios y las cuotas, entre otros aspectos. Los funcionarios del Ayuntamiento de la ciudad de México tuvieron que acatar las disposiciones borbónicas, aunque la corporación tenía ciertos acuerdos anteriores a la fecha de instauración de las reformas borbónicas que no fue posible ignorar; por ejemplo, la plaza del Volador presentaba una peculiaridad en su administración.

El dueño del espacio donde se ubicaba esta plaza era el marqués del Valle, duque de Terranova y Monteleone. Este decidió arrendarle al Ayuntamiento el lugar para que ahí se colocaran los vendedores y el contrato fue escriturado el 14 de diciembre de 1789; del arrendamiento eran 2500 pesos mensuales (Yoma y Martos, 1990, pp. 70-72). Es importante mencionar que en la plaza del Volador el asentista operó de distinta forma que en años anteriores, es decir, el Ayuntamiento le pagaba una renta al marqués del Valle por ocupar su terreno, pero este no era el cobrador de los puestos, sino un regidor del Ayuntamiento.

La principal problemática que presentó la plaza del Volador fue carecer de mantenimiento; el marqués consideraba que no era su papel y el Ayuntamiento suponía que dado que el espacio no era de su propiedad no le correspondía su reparo. "Según las leyes de arrendamiento, el locatario no tenía por qué pagar por el reparo o mejora del cajón; eso correspondía al Ayuntamiento." Este aspecto generó que la plaza se deteriorara paulatinamente y, en consecuencia, fueron frecuentes las quejas de los comerciantes por las malas condiciones de la misma (Yoma y Martos, 1990, p. 110).

El Ayuntamiento de la ciudad de México trató de remediar la situación comprándole al marqués de Monteleone el terreno de la plaza del Volador, pero le era difícil no sólo reunir el dinero, sino ponerse al corriente en los pagos atrasados. Finalmente en 1830 el Ayuntamiento logró liquidarlo y tomó posesión del mismo. En ese mismo año, la Comisión de Mercados expuso en sesiones de Cabildo la necesidad de construir e invertir en la construcción de nuevos mercados fijos, petición que ya no pudo ser resuelta en la república federal, pero sí se intentó atender en la república central (Yoma y Martos, 1990, p. 95).

Otro de los mecanismos de la municipalidad para realizar las tareas de la administración de las plazas y los mercados fue abrir contrata a particulares para el cargo de administrador de plaza. Esta modalidad se formalizó a comienzos del siglo xix y se implementó también para otros servicios públicos, como el empedrado, el alumbrado y la limpia de la ciudad; se sabe que

\section{()(1) $(9$}


los resultados no fueron del todo satisfactorios. Una de las razones se debió a que la mayoría de los contratos no se cumplían a cabalidad. Ana Lau Jaiven (2003, pp. 419-421) sostiene que las contratas se convirtieron en un negocio redondo, entre 1803 y 1850 se presentaron varias quejas de los asentistas exigiendo mayores privilegios. Lo anterior nos sugiere varias reflexiones: ipor qué se quejaban los contratistas?, ¿por qué no se cumplían a cabalidad las contratas? Es probable que los contratistas hallaron un espacio libre de gobierno y buscaron sacar provecho de la administración y, como estrategia de cobro, referían la falta de dinero para realizar sus tareas.

\section{LA CONTRATA DE ADMINISTRADOR DE PLAZAS Y MERCADOS EN LA REPÚBLICA}

Durante la primera república federal el Ayuntamiento de la ciudad de México se enfrentó a una problemática complicada: el comercio de alimentos aumentó dentro y fuera de las plazas, a la autoridad le fue difícil realizar el cobro del derecho de plaza, principalmente de las "sombras", debido a que estas eran movibles, mientras que los cajones al ser fijos estaban más controlados. En una de las reuniones en el Cabildo se abordó el tema de la regulación de comercio de comestibles y de las dificultades que ocasionaban los vendedores a mano que se encontraban diseminados por las calles de toda la ciudad. ${ }^{5}$

Entre 1828 y 1835 fue frecuente hallar en las Actas de Cabildo diversas discusiones en las que se analizaban distintas propuestas para realizar el cobro de las "sombras" en las plazas. A la municipalidad le preocupaba "la escasez de fondos y los crecidos gastos que exigía tal proyecto". Algunos regidores señalaban que dejar a particulares el cobro del "derecho de plaza" ${ }^{\text {no }}$ estaba dando buenos resultados, pues sólo "ha sido provechoso a dos o tres individuos, que nada pagan de una negociación y exclusivamente perciben todas las utilidades".

Además, agregaban los miembros del Ayuntamiento que "de acuerdo a los ingresos que se estimaban producir por la renta de sombras, se sugiere que se celebre con el mejor postor en almoneda pública". Argumentaban los regidores que así "el público no se perjudicaría formándose esta contrata por-

${ }^{5}$ Mercado. 28 de mayo de 1835. Vol. 3730, exp. 126, f. s/n. AHDF, México.

${ }^{6}$ El "derecho de plaza" fue el impuesto que el Ayuntamiento cobraba al expendio de cualquier producto.

\section{()(1) $\$$}


que la administración de mercados en ese evento solamente se ocuparía de cuidar de la exacta observancia de sus condiciones" y vigilando "que estén bien servidos los abastecedores de los mercados".

La preocupación del Ayuntamiento por buscar otras formas para recaudar y mantener el orden del crecido comercio urbano generó que la Comisión de Mercados, en conjunto con la de Hacienda, propusieran en 1835 lo siguiente: "las sombras diarias de los mercados y las que sirven en las fiestas extraordinarias se rematarán en almoneda pública en el mejor postor. La base para el remate será de 4745 pesos anuales" y bajo las siguientes condiciones:

1.- La contrata de sombras se celebrará por 3 años al mejor postor, pagando por tercios adelantados el importe.

2.- Mantendrá 8 mozos diarios para el servicio de las sombras en los mercados distribuyéndolos del mejor modo, decentes en lo que cabe, de buenos modales y educación, no viciosos, ni briagos.

3.- Tendrá el buen estado de sombras para abastecer los mercados.

4.- No se cobrará por cada sombra más de una cuartilla y sólo en festividades medio real con cada una.

5.- Para recoger las sombras se asignan los mismos lugares en que hoy se colocan en los mercados.

6.- Los mozos estarán subordinados al administrador, estos deben tratar bien a los abastecedores.

7.- Siempre que se falte a alguna de las condiciones estipuladas sufrirá una multa de 25 pesos.

8.- El contratista dará un fiador que se comprometa a responder por las resultas de esta contrata. ${ }^{8}$

Veinte días después de lanzar la propuesta, el Ayuntamiento publicó en periódicos y rotulones la convocatoria para invitar a "postores para contrata de sombras de los mercados de esta ciudad, bajo las bases establecidas". 9 Por las características de la contrata se advierte que quien postulara para el cargo de administrador de mercados debía contar con un capital económico importante para pagar la fianza inicial, asimismo, debía contar con un fiador que a su vez demostrara tener suficientes ingresos.

${ }^{7}$ Mercados. 1 de octubre de 1835. Vol. 3730, exp. 130, f. s/n. AHDF, México.

${ }^{8}$ Mercados. 1 de octubre de 1835. Vol. 3730, exp. 130, f. s/n. AHDF, México.

${ }^{9}$ Mercados. 21 de octubre de 1835. Vol. 3730, exp. 130, f. s/n. AHDF, México.

\section{(ㅇ)(1) $\$$}


Al parecer estas primeras convocatorias no tuvieron gran éxito y no se presentaron muchos postulantes, en parte porque dichas convocatorias carecían de un sustento legal, es decir, no estaban reglamentadas formalmente las contratas y, además, el Ayuntamiento aún no definía con qué recursos iba a pagar a los administradores. Esta circunstancia provocó varios fraudes de los administradores: en varias ocasiones no recibían oportunamente su pago y reportaban menos cobros para así obtener sus salarios.

En 1836 el comisionado de Mercados, Agustín Diez de la Barrera, expuso al Ayuntamiento su rechazo al sistema de contrata y solicitó que "el ramo de sombras de los mercados se administre inmediatamente por el cuerpo municipal bajo la dirección de la Comisión respectiva, y que se proceda a la brevedad a un reglamento". Agregó que el notable aumento de "vendedores en las plazas de México" era resultado del "fácil expendio que tienen sus efectos, y debido a que el recinto de los mercados no ha sido bastante para contenerlos", se han incrementado los puestos. ${ }^{10}$

Para finalizar su argumentación, Agustín Diez de la Barrera manifestó que el aumento de vendedores se debía a que "la humanidad hizo que se tolerase el uso de las sombras llegando su número hasta servirse con 500 o 700 diariamente, cuyo producto anual con las fiestas extraordinarias está calculado cerca 5000 pesos". ${ }^{11}$ La declaración del comisionado revelaba tanto su preocupación por ordenar el comercio urbano, como la oportunidad de captar mayores ingresos de la recaudación fiscal sin la intervención de terceros. El cierre de la primera república fue testigo de la falta de acuerdos dentro de la propia municipalidad respecto al comercio urbano y su gestión, la ausencia de un reglamento de mercados, y la emergencia de las necesidades de la propia ciudad propició se trasladaran los mismos problemas del comercio a la primera república central.

\section{LA CONTRATA BAJO LA PRIMERA REPÚBLICA CENTRALISTA}

El debate municipal entre abrir contrata a particulares para la administración de los servicios públicos o permitir que el propio Ayuntamiento a través de sus comisiones los administrara, culminó tras la disposición del gober-

${ }_{10}$ Mercados. 24 de marzo de 1836. Vol. 3730, exp. 130, f. s/n. AHdF, México.

${ }^{11}$ Mercados. 24 de marzo de 1836. Vol. 3730, exp. 130, f. s/n. AHDF, México.

\section{()(1) $\$$}


nador del Departamento de México Luis Gonzaga Vieyra, cuando publicó en 1840 las Ordenanzas municipales (Ordenanzas, 1884, p. 53). La finalidad de dichas ordenanzas era poner orden y dejar claras las reglas de operación en distintas áreas de la administración municipal, entre ellas, los servicios públicos para la ciudad de México.

En el capítulo i de las Ordenanzas se abordaba la importancia de los ayuntamientos de impartir la policía de salubridad, de comodidad y ornato, así como de orden y seguridad. En el artículo 16 se aclaraba que "todos los ramos municipales que se hallan a cargo de los ayuntamientos y tienen fondo destinado, en lo de adelante se administrarán precisamente por contratistas, bajo inmediata inspección y vigilancia de los mismos ayuntamientos”. Este artículo da cuenta de los problemas que los miembros del Ayuntamiento identificaron en años anteriores y consideraban de urgente resolución y, por ello, apuntaban que debía haber una mayor vigilancia municipal en la asignación de la contrata.

Las Ordenanzas agregaban que las comisiones respectivas examinarían a los contratistas para que "cumplan exacta y escrupulosamente con sus contratas". El artículo 17 especificaba que "las contratas se celebrarán en almoneda pública, previa convocatoria de postores, no más de cinco años”. Las mismas Ordenanzas, en su capítulo viII, destinado a "los mercados y su policía", señalaba que "las plazas se dividirán en calles, cajones, tinglados y puestos, entre tanto que los mercados se construirán de mampostería”.

En resumen, las Ordenanzas muestran que el consenso en el centralismo fue permitir que particulares se hicieran cargo de los servicios públicos, también se aclaraba que la contrata debía ser pública. En el caso de los mercados, sí se observa en la república central el interés del gobierno municipal por construir mercados fijos con el fin de eliminar paulatinamente las sombras que, dada su movilidad, resultaba más difícil controlarlas y realizar el cobro por derecho de plaza. Las Ordenanzas también aludían al crecido comercio urbano y, por ello, insistían que "sólo en las plazas, tiendas y casa de comercio podrán venderse comestibles, frutas, recaudo y demás, no prohibidos, de ninguna manera en las banquetas, esquinas o plazuelas; el contraventor sería castigado con una multa desde uno hasta doce reales y retirado del sitio".

Sobre el traspaso de los comercios, práctica común durante el virreinato y la república, se aclaraba que estaba prohibido, a menos que el inquilino "pagara en efectivo para la construcción, reparo o mejora de los mercados, si era puesto veinticinco pesos, si es tinglado ciento cincuenta pesos, si era cajón interior quinientos, y si era exterior seiscientos". Respecto a los horarios

\section{(ㅇ)(1) $\$$}


se estipulaba que los mercados estarían abiertos "todos los días, incluso los feriados civiles y eclesiásticos, desde las cinco de la mañana hasta en punto de las oraciones de la noche". Por último, se convenía que no se permitirían en los mercados vendedores ambulantes" (Ordenanzas, 1884, p. 45).

Para el cargo de administrador general de mercados se destinó un apartado específico en las Ordenanzas; uno de los requisitos era contar con seis fiadores de 2000 pesos, uno de ellos sería nombrado administrador segundo en caso de que faltase el primero y necesitaba tener tres fiadores. Ambos cargos eran vitalicios. El gobernador tenía "facultades para removerlos de sus cargos en caso de incumplimiento de sus deberes, por falta de fiadores o por quiebra". El administrador debía entregar informes mensuales al Ayuntamiento. Para elegir al administrador, el Ayuntamiento presentaba al gobernador y a la Junta Departamental las solicitudes de los aspirantes en sesión de Cabildo, y por votación se elegía al ganador. El sueldo del administrador general de mercados "por única indemnización y sueldo, disfrutará el diez y ocho por ciento de la total recaudación efectiva", siendo de su cuenta los que se muestran en el cuadro 1 .

En este cuadro se detallan los gastos anuales erogados por el administrador, sin embargo en las Ordenanzas no se especifica el sueldo del administrador, únicamente se señalaba que sería de 18\% del total de la recaudación. La estimación que el Ayuntamiento había hecho para el pago de administrador en 1836 era de 4745 pesos anuales. ${ }^{12}$ Es pertinente aclarar que la distinción entre fijar un salario y asignar un porcentaje en función de lo recaudado partía de la lógica de evitar fugas por parte del administrador. Es decir, si el Ayuntamiento le otorgaba un porcentaje de lo recaudado al administrador, este tenía incentivos para cobrar y reportar más, por el contrario, si el Ayuntamiento le fijaba un salario era probable que el administrador reportara menos de lo recaudado y efectuara fraude.

Durante la primera república federal se prefirió asignarle un salario de 5000 pesos anuales al administrador, sin embargo, bajo la república centralista se optó por establecer como sueldo el 18\% del total de la recaudación y permitir que corriera a cuenta de este los gastos mencionados en el cuadro 1. Esta disposición de fijar el salario del contratista y posteriormente asignarle un porcentaje de la recaudación, nos habla de cómo la gestión municipal se fue adaptando, ajustando e improvisando. Es decir, si una práctica no daba resultado, se implementaba otra, aunque no siempre mejorando las desave-

${ }_{12}$ Mercados. 1 de octubre de 1835. Vol. 3730, exp. 130, f. s/n. AHDF, México.

\section{()ㅜ(1) $\$$}


Cuadro 1. Gasto fijo anual del administrador de mercados

$\begin{array}{lr}\text { Rubro } & \text { Total pesos } \\ \text { Siete guardas de garitas } & 2047 \\ \text { Siete guardas de mercado } & 1768 \\ \text { Un guarda en Jesús } & 182 \\ \text { Un guarda en Santa Catarina } & 182 \\ \text { Un guarda en El Factor } & 182 \\ \text { Siete veladores mercado principal } & 1274 \\ \text { Dos veladores en el de Jesús } & 364 \\ \text { Tres veladores en Santa Catarina } & 546 \\ \text { Un velador en el Factor } & 182 \\ \text { Barrenderos y escobas para mercado } & 390 \\ \text { principal } & \\ \text { Barrenderos para el de Jesús } & 104 \\ \text { Barrenderos para Santa Catarina } & 71.5 \\ \text { Barrenderos para el Factor } & 94 \\ \text { Luces para mercados } & 237 \\ \text { Papel para administración y garitas } & 130 \\ \text { Arrendamiento garita Peralvillo } & 60 \\ \text { Manutención caballos } & 91 \\ \text { Vestuario doce celadores } & 330 \\ \text { Arrendamiento garita Niño Perdido } & 30 \\ \text { Suma } & 265\end{array}$

Fuente: Ordenanzas (1884).

nencias. Posiblemente esta forma de resolver la administración generó los tropiezos que hoy conocemos en la gestión municipal: poca planeación y escasa rendición de cuentas y poco diálogo entre la autoridad central y el municipio.

Finalmente, la publicación de las Ordenanzas municipales de 1840 aclaró varios puntos sobre la administración de servicios para la ciudad, dichas Ordenanzas fueron una especie de corolario que intentaba resolver viejas prácticas de la gestión administrativa y pretendía establecer un nuevo marco regulatorio. Sin embargo, es necesario subrayar que las Ordenanzas no lograron resolver otro tipo de conflictos en el quehacer de las municipalidades y

\section{(이요 $\$$}


que, además, dificultó en gran medida la puesta en marcha de varios dispositivos, como fue la falta de autogestión municipal. ${ }^{13}$

La dependencia de las municipalidades hacia el poder central se plasmó en las Actas de Cabildo. Los regidores y alcaldes cuando llegaban a acuerdos debían tener la anuencia del gobernador, de lo contrario no podían materializarlos. De esta forma, varias tareas de los ayuntamientos quedaron en propuestas sin concretarse; servicios como la limpia y alumbrado también presentaron diversas dificultades para llevar a cabo sus diligencias, los acuerdos hechos en Cabildo debían tener la anuencia del gobernador.

En el caso del comercio urbano se observa el interés municipal por reglamentarlo; no obstante, llegar a acuerdos entre la autoridad central y la municipalidad fue una ardua lucha en la primera mitad del siglo xIx. Finalmente, los más afectados de estas disposiciones fueron los habitantes de la ciudad de México, ya que el reparo de un camino, la falta de iluminación en las calles, el contar con un mercado limpio y ordenado, fueron peticiones que tardaron mucho en concederse. Lo que a continuación vamos a analizar son los intentos municipales para organizar de mejor manera los servicios públicos a través del estudio de las distintas comisiones que integraron el Ayuntamiento en tres momentos: fin del virreinato, la primera república federal y la central.

\section{LAS COMISIONES Y LOS SERVICIOS PÚBLICOS}

El Ayuntamiento de la ciudad de México, encargado de impartir los servicios públicos, delegó a través de sus comisiones la gestión administrativa de cada uno de ellos. Si bien este texto se centra en los años de 1824 a 1840, nos resulta importante mostrar un horizonte temporal más amplio para identificar los cambios en las comisiones. La gráfica 1 muestra la relación entre el número de comisiones en tres momentos, 1810-1817, 1824-1835 y 1836.

Esta gráfica tiene el propósito de mostrar la evolución de las comisiones a lo largo de tres regímenes: al finalizar el virreinato había alrededor de once comisiones, en la primera república federal se incrementó 27 , y en la primera república central se contrajo a 20 comisiones. ¿Cómo podemos inter-

${ }^{13}$ Por autogestión nos referimos a la facultad que tenían los ayuntamientos desde el siglo XVI de percibir sus propios ingresos económicos y disponer de ellos de acuerdo con sus necesidades. Los documentos de la época muestran que bajo la primera república central hubo mayor participación de los gobernadores en la vida de las municipalidades.

\section{()(1) $(3$}


Gráfica 1. Comisiones en el Ayuntamiento de la ciudad de México

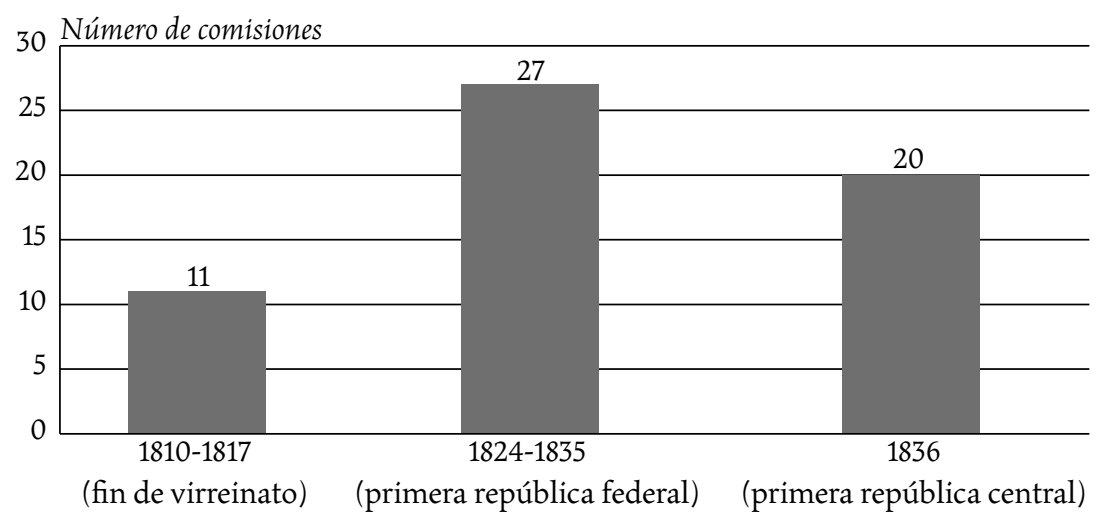

Fuente: Actas de Cabildo. 1810-1836. Vol. 135a-156a. AHDF, México.

pretar este cambio y qué representó para la población este incremento de las comisiones?, ¿mejoraron los servicios públicos?

En la gráfica 1 se observa la complejidad que fue adquiriendo la ciudad de México; lo novedoso no sólo es resaltar el incremento en el número de las comisiones de un periodo a otro, sino examinar si se crearon nuevas tareas para el Ayuntamiento o fueron las mismas. Es importante mencionar que al ampliarse el número de las comisiones también aumentó el número de regidores y alcaldes.

Para efectos prácticos de este texto hemos dividido las tareas del Ayuntamiento a partir de las comisiones existentes, y para tal fin presentamos las gráficas 2,3 y 4.

Estas gráficas representan las principales tareas que desempeñaba el Ayuntamiento, divididas en siete grandes rubros: a) Mantenimiento de la ciudad y obra pública, b) Orden y seguridad, c) Comercio urbano, d) Economía, e) Educación y salud, f) Administración y, g) Recreación.

Por Mantenimiento de la ciudad y obra pública se comprenden las actividades destinadas a la construcción de puentes, caminos o reparo de ellos, la limpia, el alumbrado y el empedrado; Orden y seguridad fueron comisiones destinadas a impartir la seguridad a los habitantes así como la vigilancia en las calles; Comercio urbano se refiere a las comisiones destinadas a verificar la venta de productos en las plazas y los mercados; en Economía se insertan

\section{(이요 $\$$}


Gráfica 2. Distribución de las tareas del Ayuntamiento de México, 1810-1817 (fin de virreinato)

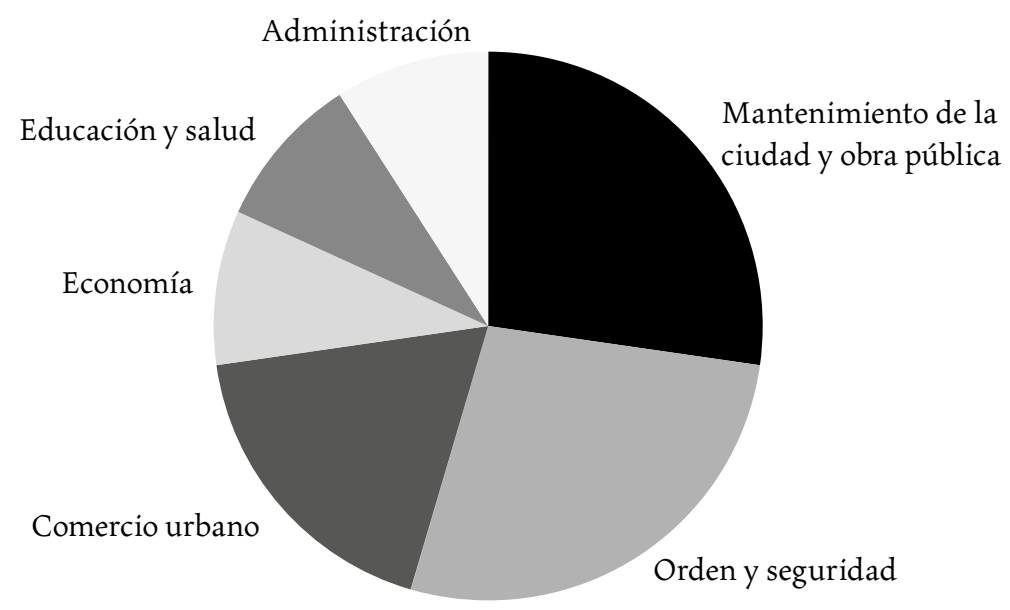

Fuente: Actas de Cabildo. 1810-1817. Vol. 135a-142a. AHDF, México.

Gráfica 3. Distribución de las tareas del Ayuntamiento de México, 1824-1835 (primera república federal)

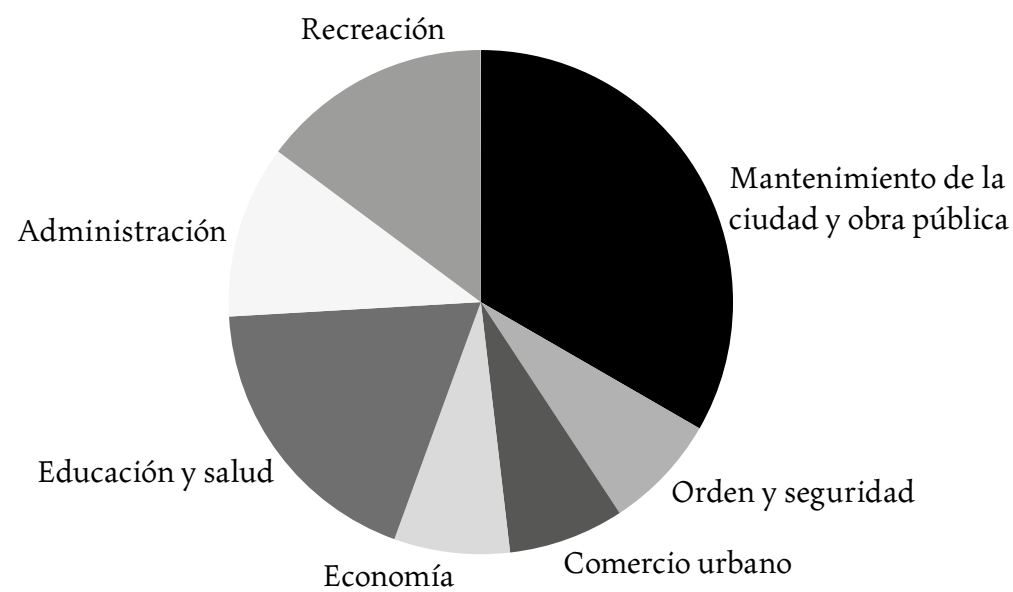

Fuente: Actas de Cabildo. 1824-1835. Vol. 149a-155a. AHDF, México.

\section{(ㄷ)(1) $(9)$}


Gráfica 4. Distribución de las tareas del Ayuntamiento de México, 1836 (primera república central)

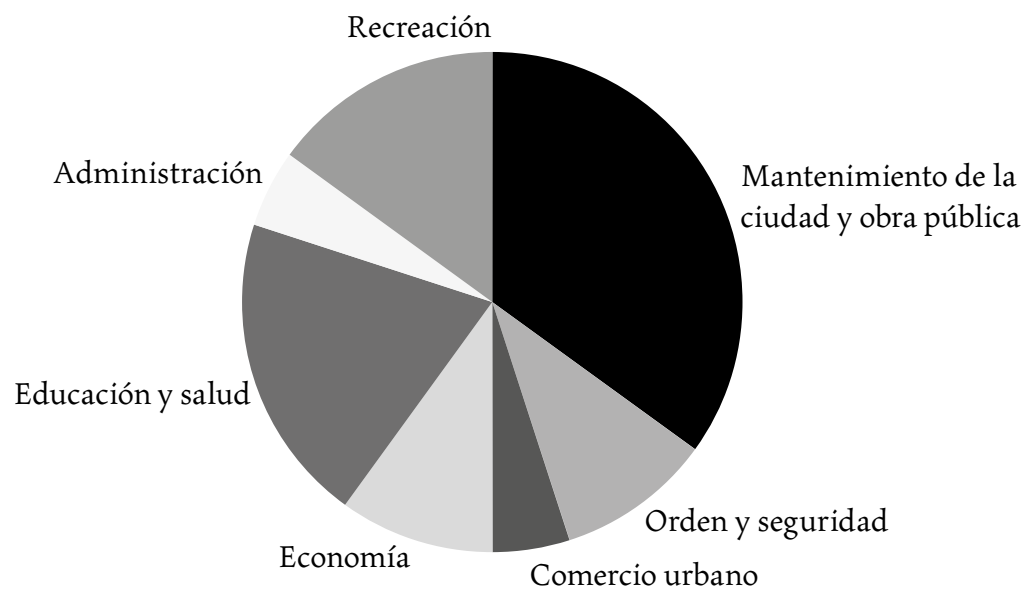

Fuente: Actas de Cabildo. 1836. Vol. 156a. AHDF, México.

comisiones que estaban al tanto de las finanzas municipales, el cobro de impuestos y la asignación de presupuestos; en Educación y salud se encuentran las comisiones encargadas de las escuelas de primeras letras y el cuidado de los enfermos en los hospitales; en Administración se hallan las comisiones facultadas para la redacción de bandos y, por último, en Recreación están las comisiones encargadas de regular las actividades recreativas de la ciudad, como las "peleas de gallos", "juego de pelota" y la lotería.

El comparativo de las gráficas 2, 3 y 4 muestra que en la primera república federal hubo un notable ensanchamiento de las comisiones encargadas de las obras públicas en relación con el virreinato o la primera república central; esta circunstancia sugiere que la municipalidad tuvo un mayor control sobre los espacios urbanos. Sin duda, lo que más se requería era el reparo de varios caminos, puentes y calles. ¿Por qué se dio este aumento en las comisiones del virreinato a la república?, ¿realmente se necesitaban más comisiones y por ello especializaron sus funciones o se trató del crecimiento de una incipiente burocracia?

Nuestra lectura apunta a que en la primera república federal se especializaron los quehaceres del Ayuntamiento en relación con el virreinato.

\section{(이요 $\$$}


Vale la pena señalar que años antes del surgimiento de la primera república federal, particularmente entre 1821 y 1823 , los temas de gobierno y administración que la Diputación Provincial y el Ayuntamiento tenían bajo su jurisdicción, ya proponían separar ciertos rubros: Hacienda pública; Tierras y aguas; Obras públicas y mejoramiento social; Seguridad pública; Instrucción pública y Proceso electoral (Salinas, 2011, pp. 90-91). Sin embargo, fue hasta 1824 cuando se formalizó.

Es probable que la especialización de las tareas del Ayuntamiento de la ciudad de México también obedeciera a la complejidad que la misma ciudad fue adquiriendo. Por supuesto, el crecimiento urbano fue uno de los factores que contribuyó para que las demandas de los habitantes aumentaran (Humboldt, 1966, p. 132; Márquez, 1994, p. 227; Moncada, 2013a, p. 143; Navarro y Noriega, 1820; Sánchez, 2004, p. 53). ${ }^{14}$ En adición al aumento poblacional, también es cierto que la institución como tal, es decir, el Ayuntamiento, consideró la posibilidad de ser más eficiente en su administración e intentó responder a las demandas de los habitantes, especializando cada una de sus áreas de gestión. Mario Barbosa (2013, p. 118) señala que para finales del siglo xix continuó esta tendencia, y el gobierno de la ciudad, en aras de tener un mayor control de la recaudación procedente del comercio urbano, intentó mejorar la eficiencia de la burocracia en el Distrito Federal.

Al finalizar el virreinato, las comisiones encargadas del Mantenimiento de la ciudad y obras públicas eran tres: Alameda y Paseos; Ríos, Calzadas y Caminos, y Alumbrado. En la primera república federal las comisiones encargadas de la misma tarea eran diez: Ríos, Calzadas y Caminos; Alameda y Paseos; Alumbrado; Empedrado y embanquetado; Aguas entrantes y salientes; Aseo y Limpieza; Coches de Providencia; Bagajes; Obrajes, y Oficinas Cerradas. Y en la primera república central se contrajo el número de comisiones destinadas al mismo rubro, quedando siete: Policía de Salubridad, Comodidad, Ornato, Limpieza y Aseo de Ciudad y Cementerio; Cárceles, Paseos, Calzadas y Caminos; Aguas, Ríos y Acequias; Alumbrado; Obrero Mayor, Embanquetados, Empedrados y Atarjeas; Coches de Providencia, y Bagajes. Esta reducción de comisiones muestra el aprendizaje del Ayuntamiento en la gestión de servicios públicos, y se observa lo que señalamos en párrafos anteriores: el intento muni-

${ }^{14}$ La población se fue recuperando a un ritmo muy lento pero constante después de finalizar la guerra de Independencia; para 1824 comenzó un periodo de relativa estabilidad y crecimiento en los niveles de la población hasta el año de 1833, la tasa de crecimiento promedio anual fue de $0.7 \%$. De 1833 a 1838 la población aumentó significativamente con respecto al periodo anterior y se presentó un crecimiento promedio anual de 3.9 por ciento.

\section{()ㅜ(1) $\$$}


cipal por hacer más eficiente la administración de la república federal a la central, ya que se redujo el número de comisiones, pero no los servicios públicos; es decir, se agruparon las tareas del Ayuntamiento en menos comisiones.

En lo que corresponde a Orden y seguridad, a fines del virreinato había tres comisiones: Policía; Milicia, y Cárcel. En la primera república federal había dos: Milicia y Cárcel; mientras que en la república central se fusionó Cárcel a otra comisión y sólo quedaron dos: Milicia y Tribunal de Vagos. Cabe destacar que la comisión de Policía no desapareció, sino se integró en una sola comisión llamada: Policía de Salubridad, Comodidad, Ornato, Limpieza y Aseo de Ciudad y Cementerio. En relación con el Comercio urbano se observa el mismo fenómeno de contracción: en el virreinato había dos comisiones: Fiel Ejecutoria y Plazas y Mercados. En la primera república federal se mantuvieron también dos: Plazas y Mercados, y apareció Pesas y Medidas. Mientras que en la primera república central quedó sólo una comisión: Mercado, Pesas y Medidas. Lo anterior es una muestra de los ajustes que se hicieron en las primeras décadas del siglo xix y los experimentos por organizar los servicios urbanos.

En el rubro Economía, a fines del virreinato estaba la comisión de Propios; en la primera república federal surgieron Hacienda, y Agricultura, Industria y Comercio. En la primera república central únicamente se mantuvo Hacienda. Al parecer esta tarea del Ayuntamiento permaneció con menos cambios, posiblemente porque la tendencia en el siglo xix fue la sujeción de las municipalidades al poder central.

En el rubro de Educación y salud las comisiones tuvieron un notable incremento a comienzos del siglo xix; en el último decenio del régimen virreinal únicamente estaba la comisión llamada Educación Pública; sin embargo, posteriormente se crearon: Educación Pública; Hospitales; Sanidad, y Casa de Beneficencia. Es importante mencionar que aunque no existían como tal las últimas tres comisiones en el virreinato, no significa que no se hubieran atendido las necesidades de los hospitales y el auxilio a los pobres, lo que aquí se resalta es que no había una comisión especializada para ello. Se sabe que en la primera república federal la Comisión de Sanidad sólo funcionaba ante una emergencia, como una epidemia; es decir, no operaba de manera continua. Y a partir de 1836 funcionaron cuatro comisiones y varias de ellas se contrajeron: Hospital de San Hipólito y San Lázaro; Hospitales; Educación y Escuelas Públicas y, Temporalidades.

Las comisiones destinadas a la gestión de Administración se incrementaron en la primera república federal con respecto a los otros dos periodos.

\section{()(1) $(9$}


Por ejemplo, a fines del virreinato sólo estaba la comisión de Archivo. En la primera república federal permaneció esta y se instauraron dos más: Formación de Ordenanzas, y Redacción de Bandos. En la primera república central se fusionaron en una sola llamada Formación de Ordenanzas y Redacción de Bandos. Nuevamente se observa que las diligencias de la municipalidad no desaparecieron del virreinato al México independiente, sino se reestructuró la administración municipal intentando cubrir las necesidades de los habitantes.

De las actividades destinadas a la Recreación de la ciudad, es importante mencionar que durante el virreinato no hubo una comisión dedicada a ello; sin embargo, en la primera república federal surgieron cuatro: Teatro; Lotería; Pelea de Gallos, y Juego de Pelota. Posteriormente, sólo permanecieron tres y se eliminó Lotería.

Para cerrar este apartado es pertinente hacer un balance sobre las comisiones que integraron el Ayuntamiento de la ciudad de México en tres momentos: fin del virreinato, la primera república federal y los inicios de la primera república central. Las gráficas 2,3 y 4 sugieren que el rubro que mayor incremento mostró fueron las comisiones encargadas del mantenimiento de la ciudad y obra pública. Dicho aumento nos habla de las necesidades y exigencias que la población de la ciudad de México demandó a las autoridades de la gran urbe. Es lógico suponer que las comisiones emanaron de una carencia no atendida en periodos anteriores. Las fuentes documentales de la época hacen referencia constantemente a la basura en las calles, presencia de perros callejeros, inundaciones, falta de drenaje y suciedad en las atarjeas, por mencionar algunos aspectos de los servicios públicos.

Una constante que se detecta al mirar la gestión municipal en su conjunto es el aumento en el número de comisiones tras la caída del régimen virreinal y la emergencia de la primera república federal, seguida de una ligera reducción de estas en la república centralista, lo cual podría considerarse como un indicador del reajuste administrativo que estas primeras décadas del siglo xix experimentaron. En las gráficas 2,3 y 4 se observa que las comisiones de la primera república federal se fusionaron bajo la primera república central. Es decir, las tareas municipales continuaron siendo las mismas; sin embargo, se trató de hacer más eficiente la gestión administrativa. Sobre todo porque las finanzas municipales de la primera república federal mostraron que la mayor erogación municipal fue el pago de salarios a los empleados del gobierno (Moncada, 2013b, p. 25).

Quienes han trabajado el papel de los ayuntamientos en la impartición de servicios públicos, opinan que una de las limitantes que enfrentó la

\section{(1)(1)}


corporación para llevar a buen cauce las distintas actividades fue carecer de recursos económicos y organización en los quehaceres administrativos (Rhi Sausi, 2000, p. 90).

El análisis anterior nos invita a reflexionar sobre ¿cuál fue el papel que desempeñaron las contratas en la impartición de los servicios públicos? Es posible que el Ayuntamiento de la ciudad de México, tras la experiencia republicana sobre los altos costos que le generó sostener la burocracia administrativa, no sólo en términos económicos, sino también en términos de concentración de la información, consideró para la primera república central que la mejor opción era fusionar algunas comisiones y dejar los servicios públicos más complicados, como la limpia y la administración de plazas y mercados a contrata.

Esta acción se plasmó en las Ordenanzas municipales de 1840, cuando se decretó que todos "los servicios públicos se administrarán por contrata". Aunque esta determinación no se echó a andar inmediatamente, esa fue la tendencia para la segunda mitad del siglo xIx. Seguramente, el Ayuntamiento consideró que las contratas harían más eficiente su gestión administrativa y, por ello, instauró ciertos dispositivos en la forma de operarlas. La más importante fue asignarle como sueldo al administrador de plazas y mercados un porcentaje del total de la recaudación y no un sueldo como se tenía en la primera república federal.

\section{REFLEXIONES FINALES}

Este trabajo apenas identificó algunos problemas que enfrentó el Ayuntamiento de México en la administración y gestión de los servicios públicos de la ciudad, Particularmente, el control del comercio urbano en las plazas y los mercados de la ciudad mostró desafíos importantes: por un lado, la falta de recursos económicos al interior de la corporación entorpeció el desempeño de las comisiones y, por otro, la carencia de organización al interior del Ayuntamiento impidió la adecuada rendición de cuentas para utilizar a la contrata como un recurso adicional en la gestión municipal.

La administración de las plazas y los mercados evidencia lo complejo que debió resultar para la municipalidad organizar el comercio en la ciudad, no sólo su cobranza, sino también mantener el orden de las sombras. Nuestras pesquisas demuestran que la venta de alimentos y otros productos de consumo cotidiano se mantuvo constante dentro y fuera de las plazas de la

\section{(1)(1)}


ciudad, y fue justo el incremento de este comercio urbano lo que orilló a la municipalidad a comisionar esta tarea bajo una contrata.

No obstante, la falta de un orden jurídico que regulara la gestión municipal provocó una mala organización y planeación en los servicios públicos de la ciudad, asimismo, se propiciaron espacios para el fraude y la corrupción. Por ello, las contratas, que parecían una salida eficiente en la administración municipal, terminaron por convertirse en negocios entre particulares, debido a la incapacidad del gobierno para vigilarlos y regularlos, así como a la falta de recursos económicos para sostenerlas.

En 1840 el Ayuntamiento de la ciudad halló nuevos dispositivos para la administración de los mercados, y a través de las Ordenanzas municipales, enunció los requisitos para ocupar el cargo de administrador y sus facultades, así como los requerimientos para obtener una contrata. El objetivo de la municipalidad era poseer un mayor control de los servicios públicos, y en particular el comercio urbano le interesaba porque las ganancias que percibía de este eran generosas frente a otros servicios.

Sin embargo, la mala planeación municipal no generó una adecuada administración de los recursos, de tal suerte que fue escasa o nula la inversión en el ramo de mercados, propiciándose así el descuido de las plazas, poca reparación de cajones y el deterioro de los puestos y sombras. Fue hasta 1850 cuando se construyó el primer mercado fijo, llamado San Juan, también conocido como mercado de Iturbide.

Por otro lado, no se presentaron condiciones idóneas para la rendición de cuentas por parte de los contratistas ni del gobierno de la ciudad. La falta de un marco normativo en el ámbito local llevó a muchos tropiezos a la administración municipal; en consecuencia, el Ayuntamiento gobernó a través de bandos y resolviendo día a día los problemas de los habitantes de la ciudad de México. Fue hasta la primera república central cuando se elaboraron las primeras Ordenanzas municipales, después de las últimas dictadas en la Constitución de Cádiz de 1812.

El incremento de las comisiones del Ayuntamiento de México fue una respuesta de la complejidad que la propia ciudad fue presentando en el primer tercio del siglo XIX, no sólo a causa del incipiente crecimiento poblacional, sino también por las tareas administrativas que la municipalidad debía cubrir; en cierta forma se dio una especialización en varios quehaceres administrativos. Al finalizar el virreinato había alrededor de once comisiones, en la primera república federal 27 y en la primera república central se redujeron a 20. En varios casos, las comisiones cambiaban de nombre aunque las tareas

\section{()(1) $(9$}


municipales continuaron siendo las mismas. No obstante, se trató de hacer más eficiente la gestión administrativa, aunque aún con muchos tropiezos.

\section{LISTA DE REFERENCIAS}

Barbosa, M. (2013). El mercado de San Juan y la descentralización del abasto en México. En A. Salmerón y F. Aguayo (coords.), "Instantáneas" de la ciudad de México. Un álbum de 1883-1884 (pp. 109-123). México: Instituto Mora/UAM-Cuajimalpa.

Gortari, H. de (2002). La ciudad de México de fines del siglo xvirI: un diagnóstico de la ciencia de la policía. Historia Contemporánea, 24, 115-135.

Humboldt, A. (1996). Ensayo político sobre la Nueva España. México: Editorial Porrúa.

Lau Jaiven, A. (2003). Las concesiones, un medio para el desarrollo de los servicios públicos de la ciudad de México: ¿un negocio redondo? En M. del C. Collado (coord.), Miradas recurrentes. La ciudad de México en los siglos XIX y XX (t. I, pp. 221285). México: Instituto Mora.

Márquez, L. (1994). La desigualdad ante la muerte en la ciudad de México: el tifo y el cólera, 1813-1833. México: Siglo XXI Editores.

Miranda, S. (1998). Historia de la desaparición del municipio en el Distrito Federal. México: Unidad Obrera y Socialista.

Moncada, G. (2013a). La libertad comercial: el sistema de abasto de alimentos en la ciudad de México, 1810-1835. México: Instituto Mora.

Moncada, G. (2013b). Las finanzas del Ayuntamiento de la ciudad de México, 18201835: un balance positivo. Estudios de Historia Moderna y Contemporánea de México, 45, 3-29.

Navarro y Noriega, F. (1820). Memoria sobre la población del reino de la Nueva España. México: s. e.

Olvera Ramos, J. (2007). Los mercados de la Plaza Mayor en la ciudad de México. México: Cal y Arena.

Ordenanzas municipales del que fue Departamento de México sancionadas por el gobierno y junta departamental en el año de 1840 y que están vigentes en la actualidad en el Distrito Federal (1884). México: Imprenta, Librería y Litografía de E. Dublán.

Quiroz, E. (2005). Entre el lujo y la subsistencia. Mercado, abastecimiento y precios de la carne en la ciudad de México, 1750-1812. México: El Colegio de México/Instituto Mora.

Rhi Sausi, M. J. (2000). Como un espectador inhábil: algunos ejemplos de la intervención del gobierno nacional en la vida financiera del Ayuntamiento durante el siglo xIX. En C. Illades y A. Rodríguez Kuri (comp.), Instituciones y ciudad. Ocho estudio históricos sobre la ciudad de México (pp. 81-112). México: Unidad Obrera y Socialista.

\section{()(1) $(2$}


Salinas, M. del C. (2011). Ayuntamientos y Diputación Provincial de México (18211823). En D. Birrichaga, A. Escobar y M. del C. Salinas (coords.), Poder y gobierno local en México, 1808-1857 (pp. 79-104). México: El Colegio Mexiquense/El Colegio de Michoacán.

Salinas Sandoval, C. (1999). Municipalidades durante la primera república federal (1825-1835). En M. del P. Iracheta y D. Birrichaga (comps.), A la sombra de la primera república federal. El Estado de México, 1824-1835 (pp. 191-207). Toluca, Estado de México: El Colegio Mexiquense, A. C.

Sánchez Santiró, E. (2004). La población de la ciudad de México en 1777. Secuencia, 60, 31-56.

Toris, G. (2014). La construcción del orden. Espacio y poder en la Plaza Mayor en la ciudad de México a fines del siglo XVIII. (Tesis de maestría inédita). Facultad de Filosofía y Letras-unAm, México.

Yoma, M. y L. A. Martos (1990). Dos mercados en la historia de la ciudad de México: el Volador y la Merced. México: INAH.

\section{OTRAS FUENTES}

AHDF Archivo Histórico del Distrito Federal, México. 